Cronfa - Swansea University Open Access Repository

This is an author produced version of a paper published in :

Language in Focus Journal

Cronfa URL for this paper:

http://cronfa.swan.ac.uk/Record/cronfa27542

\title{
Paper:
}

Milton, J. (2015). The impact of L1 lexical organisation in L2 vocabulary acquisition. Language in Focus Journal, 1 (1), 15-34.

http://dx.doi.org/10.1515/lifijsal-2015-0002

This article is brought to you by Swansea University. Any person downloading material is agreeing to abide by the terms of the repository licence. Authors are personally responsible for adhering to publisher restrictions or conditions. When uploading content they are required to comply with their publisher agreement and the SHERPA RoMEO database to judge whether or not it is copyright safe to add this version of the paper to this repository. http://www.swansea.ac.uk/iss/researchsupport/cronfa-support/ 


\title{
DE DE GRUYTER \\ OPEN
}

LIF - Language in Focus Journal, Volume 1, No: 1, 2015

DOI: $10.1515 /$ lifijsal-2015-0002

\section{The Impact of L1 Lexical Organisation on L2 Vocabulary Acquisition}

\author{
Ahmed Masrai \\ James Milton \\ Department of English Language and Literature, Swansea University, Swansea, UK
}

\begin{abstract}
This paper presents an empirical study investigating the relationship between first language (L1) lexical organisation and second language (L2) vocabulary development. The participants consisted of 191 native Arabic learners of English as a foreign language (EFL) within higher secondary education in Saudi Arabia. To conduct the study, two receptive vocabulary size tests (L1 Arabic-Lex and L2 English X-Lex) were used with an L1 lexical organisation test (ALOT) which was designed for the purpose of the study. Learners' L1 lexical organisation scores were found to be associated with their L1 and L2 receptive vocabulary scores. However, the strong correlation found between lexical organisation and the size of the lexicon in learners' L1 might well suggest that lexical networks and the size of the lexicon are one unified system. Nevertheless, to find any potential interaction between L1 lexical organisation and size on L2 vocabulary acquisition, 'moderation' analyses were performed. Moderation results revealed three levels of interaction; low, average and high. The low level shows that a low level of lexical organisation leads to low levels of L1 and L2 vocabulary size. The same relationship trend was logged for average and high levels. These results thus emphasise the importance of a well-structured L1 mental lexicon on L2 vocabulary acquisition.
\end{abstract}

\section{Introduction}

Research on second language acquisition (SLA) proposes that developing a large and well-structured L1 lexicon might enhance the potential for developing larger L2 vocabulary and lexical representations. Wolter (2006), for example, contends that L2 learners who are already in possession of a highly sophisticated and structured L1 lexicon will not completely 
disregard the L1 lexical knowledge and begin learning the L2 from the scratch. Wolter (2006, p. 741) also argues that "this lexical structure is further reinforced by a similarly sophisticated understanding of conceptual and experiential knowledge that indicates to the learner how the concepts associated with the forms in the language (be it an L1 or an L2) can be connected to each other". Thus, this kind of L1 lexical knowledge might have a great influence on how the learner structures links between words in L1 and L2.

Furthermore, considering the three-stage development model of L2 lexical entries (Jiang, 2002), this suggests that L1 lemmas (the semantic and syntactic information) can play an important role in supporting the learner when acquiring L2 words, then it can be argued here that it is inescapable that L2 learners, particularly for those at a low-level, will map L1 meaning to the existing L2 word form. This indicates that L1 lemma mediation is a significant feature of learner lexical development, at least at a certain stage. In the same vein, Snow and Kim (2007, p. 124) raise the question "...do learners with large L1 vocabularies easily acquire vocabulary in the L2?". Masrai and Milton (forthcoming) have attempted to find an answer for the question proposed by Snow and Kim (2007). Their study shows that a learner who possesses a large L1 lexicon tends to develop a sizeable L2 lexicon.

Another point addressed by Wolter (2006, p. 742) is that "a complex set of assumptions for assimilating and structuring L2 lexical knowledge is already well in place before learners learn their first word in the L2". These assumptions, as Wolter suggests, are generated from a well-established lexical network that a learner has built through knowledge of concepts and links between lexical items in his/her L1. However, the caveat might be the misinformation about allowable combinations of L2 words that L2 learners will be provided with based on L1 lexical patterns or incomplete knowledge. Yet, if the L2 learner utilises the knowledge of L1 lexical structures to build an L2 lexical network, at least to a certain extent in the initial stages of learning, that would be very useful.

Taking the discussion above into consideration, one can conveniently propose that L2 learners with a well-structured L1 lexicon will operationalise this feature in developing an L2 lexicon. This study is therefore an attempt to investigate the relationship between L1 Arabic mental lexicon organisation and L2 English vocabulary acquisition.

\section{Relationship between L1 and L2 mental lexicons}

It is inevitable that learning any new language vocabulary is not an easy task and demands great effort by both language learners and teachers. The degree to which difficulties exist varies and is subject to several issues. One issue is the relationship between L1 and L2 mental lexicons.

The mental lexicon is a complex structure that stores the lexical items a speaker of a language possesses. Singleton (1999) points out that:

[The] mental lexicon is understood by linguists as the constituent of components of a language or knowledge of a language which has to do with what one might call 'local' phenomena - the meanings of particular elements of a given language, the phonological and orthographic forms of these elements, and the specific ways in which they collocate and colligate (Singleton, 1999, p. 15). 
Aitchison (2003), on the other hand, describes the mental lexicon by stating that:

[The] mental lexicon is concerned above all with links, not locations ... it pays attention to cores of words, rather than peripheries, since it is impossible to say where knowledge about a word ends ... frameworks are more important than details, which are filled in creatively as speech proceeds ... the lexical connections in the mind are far from what we normally imagine a dictionary or lexicon to be (Aitchison, 2003, p. 248).

It seems possible to believe that when someone speaks more than one language, he/she has more than one lexicon, regardless of the lexicons' locations in the mind. However, the situation is far more complex as the discrepancies abound about the relationship between these mental lexicons. There are several studies addressing the issues related to lexical processing, lexical organisation and lexical access (e.g., De Groot, 1993; Kroll et al., 2002; Singleton, 1999; Wolter, 2001). Thus, these issues are largely addressed in the literature related to how two language systems become connected to each other in the mind of a bilingual learner. This section will present arguments from different points of view about the relationship between L1 and L2 mental lexicons and the influence that the L1 lexicon might have on L2 vocabulary acquisition.

One side of the debate about the mental lexicon (Meara, 1984, 1992, 1996) contends that the L1 and L2 mental lexicons are structurally different in terms of quality. This line of research claims that the L1 lexicon is mainly semantically organised, while words stored in the L2 lexicon are phonologically related. However, Meara (2009) also argued that the L2 lexicon might change to be more like the L1 lexicon as learners become more proficient. This conclusion was drawn from data collected using word association tests performed by both L1 and L2 learners. Another line of research (e.g., Littlewood, 1984; Carroll, 1992; Singleton, 1999 ) is in favour of a single system. In this view, the principle of organisation for both L1 and L2 is semantic. Lexical items are argued to be classified into semantic categories, each of them being further subdivided into a set of L1 and L2 lexical units. In a study by Channell (1988, cited in Ma, 2009) that explored L1 and L2 speech errors, both L1 and L2 learners performed similarly in the task given, implying that L1 and L2 lexicons resemble each other in that words become phonologically arranged and related by semantic links (De Groot, 1993; Singleton, 1999).

Weinreich (1974, cited in Agustín Llach, 2011) points out how two lexicons relate to each other in the mind of a bilingual learner. In his view, three conceptualisations can be proposed according to the relationship between the L1 and L2 mental lexicons: (1) coordinate, in which two separate form-meaning links coexist in the mind of the learner; (2) compound, where bilinguals have a single concept associated with two different words; and (3) subordinative, in which the L1 word form mediates between the L2 concept and the L2 word form. Weinreich (1974) claims that the relationship between L1 and L2 lexicons, in light of the three different types of connections he proposed above, is not stable but relies on the learner's experience with L2 and different types of lexical organisation may coexist in the same mind (Agustín Llach, 2011). Some research supports Weinreich's (1974) claim that the subordinative relationship between L1 and L2 lexicons is associated with poorly proficient L2 learners, while a compound association exists with highly proficient learners (e.g., De Groot, 1993; Kroll et al., 2002). In the same vein, Van Hell and Kroll (2013) argue that when L2 learners' proficiency increases the ability to access concepts for L2 words becomes stronger, which leads to a high level of lexical-to conceptual mappings that are equivalent to those in L1 for bilinguals who are highly proficient in both L1 and L2. 
Nonetheless, there are other factors which can influence the relationship between L1 and L2 lexicons, such as the formal or semantic similarity perceived between the L1 and L2 words, or importantly the learning environment, which is how the word has been acquired (Singleton, 1999). Additionally, there are also the claims that (1) L2 lexical forms are most likely mapped to the existing semantic content of their L1 translations instead of mapping them to new semantic specifications of their own (Jiang, 2002); and (2) that L1 lexical/conceptual knowledge relates to the structuring of L2 lexical networks (Wolter, 2006). Firstly, in accordance with the first point, it is conceivable that L2 lexical forms can be mapped to new meanings or concepts which are developed during the process of L2 vocabulary acquisition or to the meanings or concepts already in the existing semantic or conceptual L1 system. The assumption regarding mapping L2 words to the existing L1 meanings or concepts has been long acknowledged in the literature of SLA. Ausubel (1964, p. 421), for example, suggests that "L2 learning processes should be easier for adults than for children due to the fact that adults need not acquire thousands of new concepts but merely the new verbal symbols representing these concepts". Some recent research, however, (e.g., Ringbom, 1983; Giacobbe, 1992) suggests that L2 vocabulary learning begins with mapping processes to the existing L1 concepts, and as L2 experience and proficiency develop, restructuring of concepts then takes place which eventually leads to the remapping of forms to new concepts.

Considering the different views of lexical representation in the L2 mental lexicon, mapping L2 words to the existing meanings or concepts in the L1 system is one of the acquisition stages that L2 vocabulary learning needs to go through. A question is raised, however, about whether the idea of mapping L2 words to the existing L1 meanings or concepts takes place without a highly organised L1 mental lexicon.

The second point concerns the role of L1 lexical/conceptual knowledge in developing L2 lexical network structure and its relationship with L2 vocabulary acquisition (Wolter, 2006). Predictably, before a learner is involved in the processes of SLA, he/she has already built up an extensive knowledge of concepts and a general knowledge of the world. However, the degree to which this knowledge is transferable to help the development of L2 lexical knowledge is undeniably subject to other factors, such as lexical similarity between the native and target languages, and any marked overlap between the lexical networks in the L1 and L2. Nevertheless, a clean start for L2 learning is not likely as argued by some researchers (e.g., Ausubel, 1968; Wolter, 2006).

Wolter (2006, p. 741) argues that "it is certain that post-pubescent L2 learners are already in possession of a highly sophisticated L1 lexicon ... surely, this L1 lexical/conceptual knowledge has a massive influence on how the learner structures connections between words in an L2". He further contends that there is no logical reason to accept that L2 learners would relinquish their L1 knowledge when they initially approach L2. This is not to depend solely on the role of the L1 lexical knowledge for L2 lexicon structure and vocabulary learning, but to fairly argue that it is implausible that L2 learners will entirely ignore their existing L1 knowledge and begin L2 lexical acquisition from scratch. Nonetheless, it should also be indicated that L1 lexical/concept knowledge would not invariably assimilate new L2 lexical items correctly into the L2 mental lexicon. For example, Laufer (1991) suggests that lexical similarity between the L1 and L2 might sometimes lead to misconception, the 'false friend' phenomenon, about allowable combinations of L2 words (collocations). 
From the evidence provided above, it can be perceived that a well-developed L1 lexicon would be, to a great extent, a facilitator for L2 lexicon development. However, there are various instances where lexical relabeling processes would not take place, as there are totally new concepts that are language specific. Some concepts may reflect cultural specificities of the community of the target language which are structured and distributed in a different way from the L1 and will be problematic to L2 learners (Singleton, 1999). The studies concerned with the relationship between L1 and L2 mental lexicons are extensive and are therefore beyond substantial review here but practically limited to the overview offered above.

Nonetheless, it is argued that whatever the aptitudes that enable a child to obtain a well-developed L1 lexicon, they are probably also accessible to support the acquisition of an L2 lexicon. Thus, one might well expect a positive correlation. For example, unlike a learner who has poor L1 lexical organisation, an L2 learner who has already developed L1 lexical networks might only apply relabeling for the existing L1 vocabulary knowledge and only create new concepts for those which are not structured and available in his/her L1 mental lexicon. Although this kind of relationship between L1 and L2 lexicons might well exist, it is still an area that has not been adequately investigated. Therefore, the current study attempts to tackle this question and is hoped to contribute to the field of vocabulary teaching and learning in general and to the Saudi context in particular.

\section{The study}

The study aims to find out if there is a relationship between L1 (Arabic) lexical organisation and L2 (English) vocabulary acquisition. The study's hypothesis is that if the newly devised L1 Arabic lexical organisation measure (ALOT) is working well, a strong correlation between learners' scores and the scores from the Arabic-Lex test should be seen (Masrai \& Milton, forthcoming). This claim is supported by research into Arabic morphological structure and lexical representation (e.g., Frost, Froster \& Deutsch, 1997; Boudelaa \& Marslen-Wilson, 2005; Boudelaa et al., 2010; cited in Boudelaa \& MarslenWilson, 2010). These studies claim that experimental research into other Semitic languages, specifically Hebrew, emphasise the primacy of morphemes, indicating how roots and word patterns govern lexical organisation and lexical processing in this language family. Therefore, the test designed for the purpose of the current study is argued to be appropriate.

This study aims to achieve the following objectives:

1. Investigate the effects of L1 lexical organisation on L2 vocabulary acquisition.

2. Explore the relationship between L1 lexical organisation and L1 vocabulary knowledge.

3. Explore whether a moderation interaction can be found between L1 lexicon size and organisation and L2 lexicon size; and

4. Validate the findings from Masrai and Milton (forthcoming) about the established relationship between L1 (Arabic) and L2 (English) vocabulary size.

\section{Method}

\subsection{Participants}


The participants who took part in the study consisted of 191 male students attending two secondary schools in Saudi Arabia. They were all randomly selected from the final three secondary school levels. The ages of the participants varied from 16 to 18 years old. The purpose of using participants from secondary school levels, and not including learners from earlier levels, is the assumption that learners at these higher levels are predicted to have developed a better-structured L1 lexicon. In support of this claim, Kersten (2010), Schmitt (2000) and Wolter (2006) contend that the levels of lexical organisation in the mental lexicon are largely linked to the vocabulary size of an individual. Three tests were administered to the participants in this study, namely Arabic-Lex test (Masrai \& Milton, forthcoming), X-Lex test (Meara \& Milton, 2003) and L1 Arabic lexical organisation test (ALOT) developed by the researchers for the purposes of the study. Details of these tests are presented in the following section.

\subsection{Materials}

To the best of our knowledge, there is no documented test for lexical organisation in Arabic that measures students' ability to generate new inflected and derived words from base forms. The required test should also predict how well learners can use appropriate word forms, either inflectional or derivational morphological endings in context. A test of this kind would seek to indicate if a learner has developed a well-structured L1 mental lexicon. For this purpose, the researchers designed a new test construct to achieve the aims of this study. In addition to the overall aim of producing reliable scores and a valid construct, a number of other main concerns were observed. Firstly, a test was constructed that made use of a large number of test items, but which simultaneously would not take a long time to administer. This was achieved by creating a test of receptive lexical/morphological knowledge. Secondly, construction of a test that would be easy to mark and score was sought, producing data that could be quantitatively analysed. Thirdly, it was proposed that at least 28 to 30 items should be included in the test for its results to be generalised (Nation, 2001). Therefore, 50 items were included in the test devised for the purposes of this study (a copy is provided in Appendix A).

The lexical organisation measure used in this study is a sentence completion task. In order for learners to complete the sentences, they had to choose the correct form of words from the given choices. Sentences were structured to be of varying levels of difficulty. After the test was constructed, it was revised and agreed upon by two Professors of Arabic applied linguistics. The other two tests employed in the current study were the Arabic-Lex test (L1) and the X-Lex test (L2). Firstly, the Arabic-Lex was used to measure participants L1 total vocabulary knowledge. The test construct enjoys the capacity of estimating the knowledge of the most frequent 50,000 words, lemmas, in Arabic. Secondly, the X-Lex test is a welldocumented measure for estimating L2 learners' total vocabulary knowledge and profile. Arabic-Lex and X-Lex tests are provided in Appendices B and C.

\subsection{Procedures}

The tests were administered during class time. The teachers and vice-principals of both schools were happy to offer the time required to administer the tests. Likewise, the informants were also enthusiastic to perform the tests. Before distributing any test, clear instructions about the purpose of the test were explained, one at a time. The X-Lex test was administered first. After having collected the X-Lex sheets, the ALOT was given to the 
participants. The same procedure was followed for the Arabic-Lex test after the participants had had a short break.

\subsection{ALOT scoring system}

The marking and scoring system of the ALOT is straightforward. Each correct answer has a weighting of one point and each wrong or unanswered question has a weighting of zero points. The overall score is a product of counting every correct answer. Using the numerical scoring system allows entry of the data into SPSS for analyses to be relatively easy. The total score for each informant was processed using SPSS along with his scores for total vocabulary knowledge from the Arabic-Lex and X-Lex tests.

\section{Results and discussion}

The following presents the results and discussion of the findings obtained from the study. The first subsection examines the relationship between L1 and L2 vocabulary size. The second subsection investigates the potential effects of L1 lexical organisation on L1 vocabulary knowledge and L2 vocabulary acquisition, together with an examination of the moderating effect of L1 Arabic lexical organisation on the relationship between L1 Arabic vocabulary size and L2 English vocabulary size.

\subsection{Relationship between $L 1$ and $L 2$ vocabulary size}

This part of the results presents Pearson correlations between L1 Arabic and L2 English vocabulary size. Results presented in Table 1 reveal a strong correlation coefficient $(r=0.799, p<.001)$ between L1 Arabic and L2 English vocabulary size. This significant correlation suggests that when a learner possesses a larger L1 vocabulary size he/she tends to have a greater L2 vocabulary. This finding appears consistent with the finding reported by Masrai and Milton (forthcoming). They found that the correlation coefficients between learners' scores in the X-Lex test (L2) and the Arabic-Lex (L1) test were strong at higher school levels $(r=0.800, p<.001)$. The Pearson correlations between L1 vocabulary size and L2 vocabulary size are almost identical in both studies. Thus, the results from the current study confirm that (a) the measurements used in both studies are valid and reliable in predicting learners' receptive vocabulary knowledge in both L1 and L2 at repeated intervals, and, (b) there is a relationship between L1 and L2 vocabulary size.

\begin{tabular}{llcc}
\hline & \multicolumn{1}{c}{ X-Lex } & Arabic-Lex \\
\hline \multirow{3}{*}{ X-Lex } & Pearson Correlation & - & $.799^{* *}$ \\
& Sig. (2-tailed) & & .000 \\
& $\mathrm{~N}$ & 191 & 191 \\
\hline \multirow{2}{***}{ Correlation is significant at the 0.01 level (2-tailed). }
\end{tabular}

Table 1. Correlations between L1 and L2 vocabulary size

This evidence supports the argument that there is a link between L1 vocabulary size and the ability to acquire a larger L2 lexicon. However, building a well-structured L1 lexicon passes through various development stages, which should not be ignored when attempting to compare it to an L2 lexicon. In other words, if a learner possesses a large vocabulary in 
his/her L1 it is not necessarily the case that he/she can have the same size L2 lexicon. Nonetheless, the well-established L1 lexicon can facilitate the learning process of L2 lexical items. Singleton (1999, pp. 189-190) states that "although the L2 mental lexicon and L1 mental lexicon are separately stored, they are connected with each other and are in communication". Wolter (2006, p. 741), conforming to Singleton, argues that "there is a strong influence [by the] L1 mental lexicon on the L2 mental lexicon". It is also held by Bastkowski (2010) that the notion of a 'clean' L2 mental lexicon is not likely since, even if the L2 learner may not know the L2 word, for example the word rain, the concept is already in place in the learner's L1 lexicon. Therefore, one can argue that when concepts for L2 lexical items are already existent in the L1 mental lexicon, L2 learners will only need to perform a relabeling process for those words. The following section reports the findings and discussion of the relationship between L1 lexical organisation and development of L1 and L2 lexicons.

\subsection{Effects of $L 1$ lexical organisation on $L 1$ vocabulary knowledge and L2 vocabulary acquisition}

To test if there is an effect of L1 lexical organisation on L2 vocabulary acquisition and L1 vocabulary knowledge, Pearson correlations and linear regression analyses were performed for this part of the data. Table 2 provides an overview of the correlation coefficients produced for the scores from the three tests employed in this study. As can be seen from Table 2, the results show a significant correlation coefficient $(r=0.747, p<.001)$ between learners' scores in the L2 vocabulary size test (X-Lex) and ALOT. The results also illustrate a strong correlation $(r=0.895, p<.001)$ between learners' performance in the ALOT and their L1 vocabulary size, measured by the Arabic-Lex test. The latter is not surprising, as developing a well-organised L1 lexicon should normally lead to building a larger L1 vocabulary. Nevertheless, explorations of this kind might provide further explanation of how an L1 Arabic mental lexicon is structured, which is hoped to highlight some of the key issues related to the consistently poor EFL vocabulary uptake by native Arabic learners in general and Saudi school learners in particular (Al-Hazemi, 1993; Alsaif, 2011).

\begin{tabular}{lccc}
\hline & X-Lex & Arabic-Lex & ALOT \\
\hline X-Lex & - & $.799^{* *}$ & $.747^{* *}$ \\
Arabic-Lex & - & - & $.895^{* *}$ \\
ALOT & - & - & - \\
\hline
\end{tabular}

**. Correlation is significant at the 0.01 level (2-tailed).

$N=191$ in all tests.

Table 2. Inter-correlations between learners' scores in X-Lex, Arabic-Lex and ALOT

To explore the data more thoroughly and estimate the quantitative effect of L1 lexical organisation on both L1 vocabulary size and L2 vocabulary size, linear regression analyses were implemented in two parts. The first part deals with analysis of the data corresponding to the relationship between L1 lexical organisation and L1 vocabulary knowledge and the second part deals with the effect of L1 lexical organisation on L2 vocabulary acquisition. 
Results presented in Table 3 show a statistically significant effect of lexical organisation on the size of the L1 mental lexicon $(F=764.618, d f=1,189, p<.001)$. As can be seen, there is a linear relationship between L1 lexical organisation and L1 vocabulary size. The $R$ square value $\left(r^{2}=0.802\right)$ suggests that L1 lexical organisation explains $80 \%$ of the variance of the regression model. Figure 1 illustrates the model graphically. The lexical organisation influence on L1 vocabulary size can clearly be seen from the scattergram, as the increase in lexical organisation of knowledge results in an increase in learners' L1 vocabulary size.

\begin{tabular}{cccccccccc}
\hline & & & & \multicolumn{5}{c}{ Change Statistics } \\
\cline { 5 - 9 } Model & $R$ & $R^{2}$ & Adjusted $R^{2}$ & $S E$ of estimate & $R^{2}$ Change & F Change & df1 & df2 & Sig. F Change \\
\hline 1 & $.895^{\mathrm{a}}$ & .802 & .801 & 4926.37804 & .802 & 764.618 & 1 & 189 & .000 \\
\hline
\end{tabular}

a. Predictors: (Constant), ALOT score.

Table 3. Regression analysis for the effect of L1 lexical organization on L1 vocabulary size

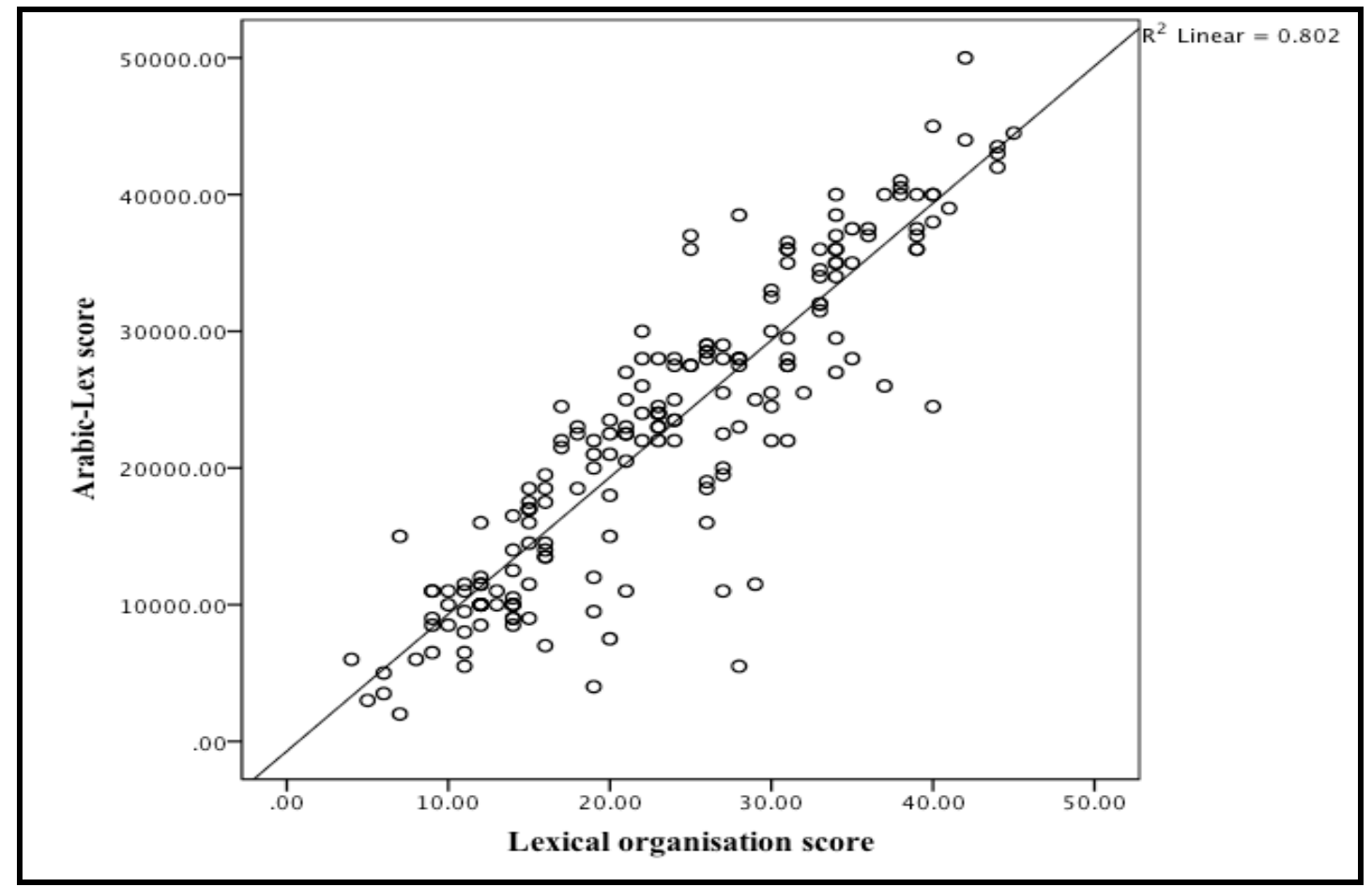

Figure 1. Scatter-plot for the best regression line fit for the relationship between L1 lexical organisation and L1 vocabulary size

The scattergram indicates that the points representing the relationship between lexical organisation and vocabulary knowledge appear to be tightly clustered around the regression line, suggesting that the model is robust. The findings are in line with the assumptions reported by studies of Abu-Rabia (2002) and Habash (2010), suggesting that the Arabic language is a highly inflectional and derivative language and that when highly regular rules are mastered then deriving new words from roots is relatively easy. This study measured the 
learners' ability to use derived word forms appropriately in order to complete sentences. Therefore, learners who have a good knowledge of rules were found to have a well-organised lexicon, which results in possessing a larger L1 vocabulary size. This observed, strong relationship between lexical networks and the size of the lexicon in the Arabic language, although interesting, per se, was not the main intention of this paper. The main aim, however, has been to explore whether the organisation of the L1 mental lexicon has a significant influence on L2 vocabulary size development, though the idea of investigating the relationship between lexical organisation and vocabulary size in L1 Arabic and their influence on L2 vocabulary learning could establish grounds for further research in this area. Additionally, to the best of the researchers' knowledge, no documented study in the literature was found to measure this kind of inter-relationship, which makes the effort worthwhile.

The study is set primarily to investigate the relationship between L1 Arabic lexical organisation and L2 English vocabulary acquisition. This part of the paper, therefore, will be devoted to presenting the findings about the nature of the revealed relationship between L1 lexical organisation and L2 vocabulary size. However, before reporting the results, it is worth mentioning that after examining the correlation matrix, 'collinearity' was found to be present between Arabic-Lex scores and ALOT scores. The collinearity is confirmed by running collinearity diagnostics using SPSS software. The correlation indicator suggests that they correlate to each other very highly $(r=0.895, p<.001)$. Consequently, this issue was dealt with by dropping the Arabic-Lex scores variable from the regression analysis. The probability for this high correlation will be discussed later in this section.

The results for the relationship between L1 Arabic lexical organisation and the potential L2 vocabulary acquisition are shown in Table 4 and Figure 2. As can be seen from Table 4, the regression model explains nearly $56 \%$ of the variance $(F=239.332, d f=1,189$, $p<.001)$. The effect of L1 lexical organisation on L2 vocabulary acquisition is statistically significant. This significant effect suggests that when learners develop a well-organised L1 lexicon they can utilise this knowledge in learning vocabulary in the L2. This relationship can be clearly seen in Figure 2. The scattergram demonstrates that learners who show a good level of L1 lexical organisation have better L2 lexis scores. The linear regression line and the tight clustering of the scores around the diagonal appear persuasive to confirming the influence of L1 lexical organisation on L2 vocabulary acquisition. This is not to argue that the Arabic mental lexicon is structured in a similar way as the English mental lexicon, but to suggest that there are features of the L1 mental lexicon networks which can be transferred when learning an L2 (Singleton, 1999; Wolter, 2006).

\begin{tabular}{cccccccccc}
\hline & & & & \multicolumn{5}{c}{ Change Statistics } \\
\cline { 5 - 9 } Model & $R$ & $R^{2}$ & Adjusted $R^{2}$ & $S E$ of estimate & $R^{2}$ Change & F Change & df1 & df2 & Sig. F Change \\
\hline 1 & $.747^{\text {a }}$ & .559 & .556 & 456.86643 & .559 & 239.332 & 1 & 189 & .000 \\
\hline
\end{tabular}

a. Predictors: (Constant), ALOT score.

Table 4. Regression analysis for effect of L1 lexical organization on L2 vocabulary size 


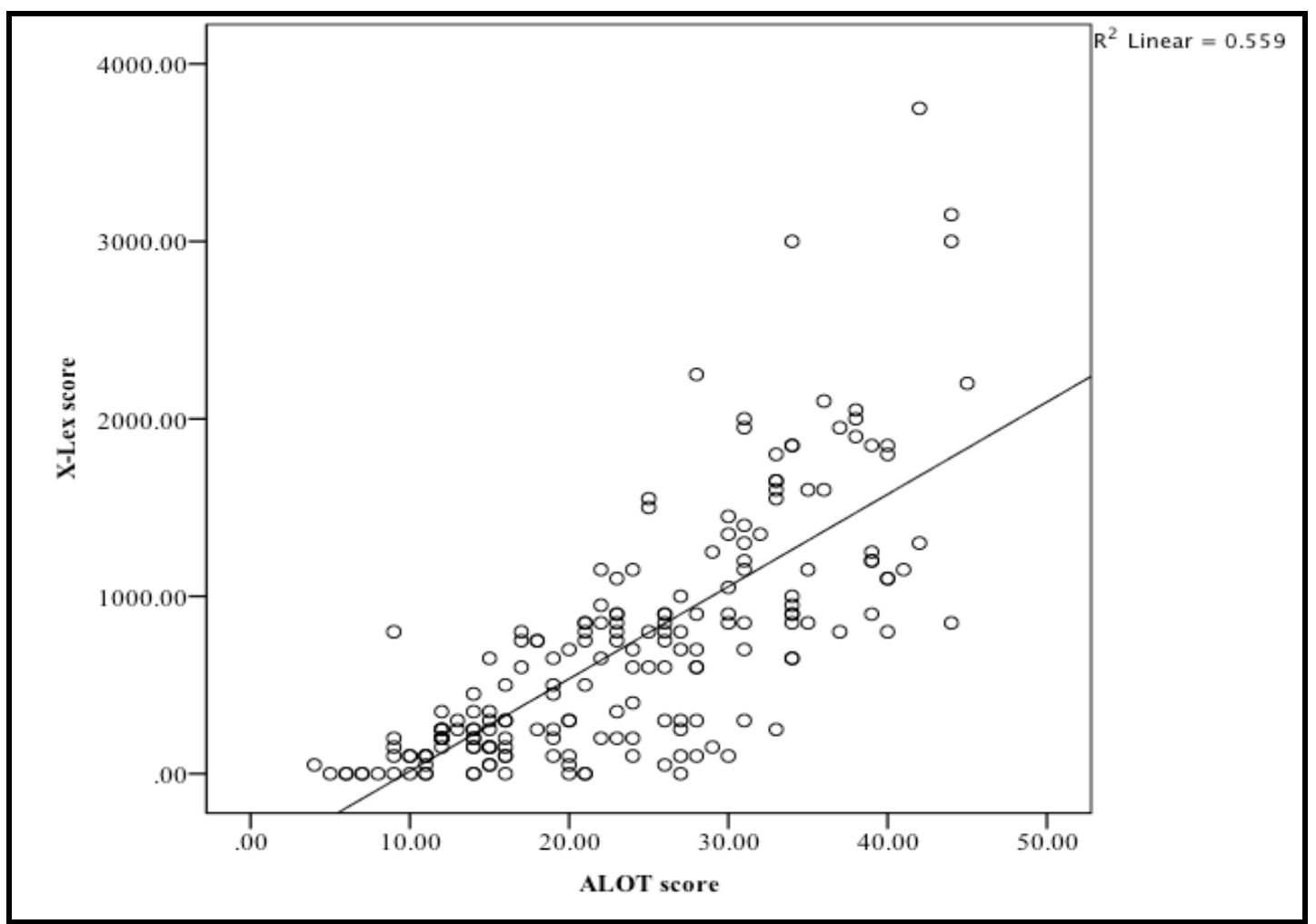

Figure 2. Scatter-plot for the best regression line fit for the relationship between L1 lexical organisation and L2 vocabulary size

It is worth pointing out, however, that the finding reported here about the kind of relationship between L1 lexical organisation and L2 vocabulary size could be a causal effect of the regularity of rules, which might be a notable aspect of the Arabic language. Therefore, interpretation of this finding and generalisation might only be considered for L1 Arabic at this stage, and further research to investigate the relationship between L1 lexical organisation and L2 vocabulary acquisition, using data from different L1 backgrounds, could provide further useful information. Nevertheless, this finding is helpful in terms of understanding the nature of the relationship between L1 Arabic and L2 English mental lexicons, which is an under-explored area.

The final set of data in this paper elaborates on the finding discussed earlier relating to the association between L1 Arabic lexical organisation and the largely developed L1 Arabic mental lexicon. It is quite difficult for an attempt to be made to disassociate the structure of the mental lexicon from its size. However, an attempt could be made to look at the interaction between the structure and size of L1 mental lexicon and the causal effect on L2 vocabulary acquisition. One possible way to test the interaction between these variables is by performing a regression analysis to assess 'moderation'. Conceptually, a moderator could be defined as the variable that modifies the effect of a predictor on a dependent variable (Tang, CritsChristoph \& Tu, 2009; Field, 2013).

In order to run this analysis, a Process plugin for SPSS developed by Field (2013) was employed. This analysis tests the moderating effect of L1 Arabic lexical organisation on the 
relationship between L1 Arabic vocabulary size and L2 vocabulary size. Table 5 shows the summary of the regression model for moderation.

\begin{tabular}{llllccc}
\hline & & & \multicolumn{4}{c}{ Change Statistics } \\
\cline { 4 - 7 } Model & $R$ & $R^{2}$ & F Change & df1 & df2 & Sig. F Change \\
\hline 1 & $.831^{\text {a }}$ & .691 & 135.8038 & 3 & 182 & .000 \\
\hline
\end{tabular}

a. Predictors: (Constant), ALOT score; Arabic-Lex score.

Table 5. Regression analysis for interaction between L1 lexical organization, L1 vocabulary size and L2 vocabulary acquisition

\begin{tabular}{lcccccc}
\hline & Coeff & $\mathrm{Se}$ & $T$ & $P$ & LLCI & ULCI \\
\hline Constant & 600.3025 & 39.4982 & 15.1982 & .0000 & 522.3692 & 678.2358 \\
ALOT & 15.3578 & 6.6704 & 2.3024 & .0224 & 2.1965 & 28.5191 \\
Arabic-Lex & .0355 & .0059 & 6.0388 & .0000 & .0239 & .0472 \\
Int_1 & .0011 & .0004 & 2.7296 & .0070 & .0003 & .0019 \\
\hline
\end{tabular}

Interactions: int_1 Arabic-Lex $\mathrm{X}$ A LOT

Note. LLCI = Lower limit confidence interval; ULCI = Upper limit confidence interval.

Table 6. Moderation model summary

\begin{tabular}{ccccccc}
\hline ALOT & Effect & SE & $T$ & $P$ & $L L C I$ & $U L C I$ \\
\hline-9.7738 & .0246 & .0063 & 3.9196 & .0001 & .0122 & .0370 \\
.0000 & .0355 & .0059 & 6.0388 & 0000 & .0239 & .0472 \\
9.7738 & .0465 & .0079 & 5.9105 & .0000 & 0310 & .0620 \\
\hline
\end{tabular}

Note. LLCI = Lower limit confidence interval; ULCI = Upper limit confidence interval.

Table 7. Conditional effect of Arabic-Lex score on X-Lex score at values of the moderator (ALOT score)

As can be seen from Table 5, the regression model suggests that both L1 Arabic vocabulary knowledge and lexical organisation combined together can explain about $70 \%$ of the variance $(F=135.8038, d f=2,182, p<.001)$ in learners' L2 vocabulary scores. However, when the effect of these two variables on L2 vocabulary acquisition was tested individually, a similar causal effect was obtained. This can confirm that vocabulary knowledge and lexical organisation in a language is more or less the same thing. This study, however, has gone a step further to assess the interaction between L1 vocabulary knowledge and lexical organisation on the effect on L2 vocabulary acquisition.

In the moderation model summary, reported in Table 6 , the interaction between L1 Arabic vocabulary size and lexical organisation is significant $(p<.01)$. This kind of interaction is confirmed by the analysis of the conditional effect from the Arabic-Lex' score 
on the X-Lex score at values of the moderator (ALOT score). The conditional effect figures reported in Table 7 show that lexical organisation is crucial in building a bigger L1 mental lexicon, which predicts an effect on L2 vocabulary acquisition, as revealed in the model. The table also shows that the effect of L1 lexical organization on the relationship between L1 vocabulary size and L2 vocabulary size is significant at all three levels of lexical organisation. The levels, as reported in Table 7, are low, average and high. In the first column under ALOT, the negative score, zero score and positive score represent the low, average and high levels of lexical organisation, respectively.

When looking at the $p$ value in Table 7, it can be clearly seen that a low level of L1 mental lexicon organisation indicates a low level of L1 vocabulary knowledge, which leads to a low L2 vocabulary size. Additionally, the same effect is shown at the average and high levels of organisation. The interaction effect is demonstrated visually in Figure 3. The figure illustrates that when a learner shows a low level of lexical organisation he/she also shows low levels of L1 and L2 vocabulary knowledge. This suggests that organisation and size of the mental lexicon cannot be separated from each other or treated as two different linguistic elements, but rather dealt with as a highly associated construct.

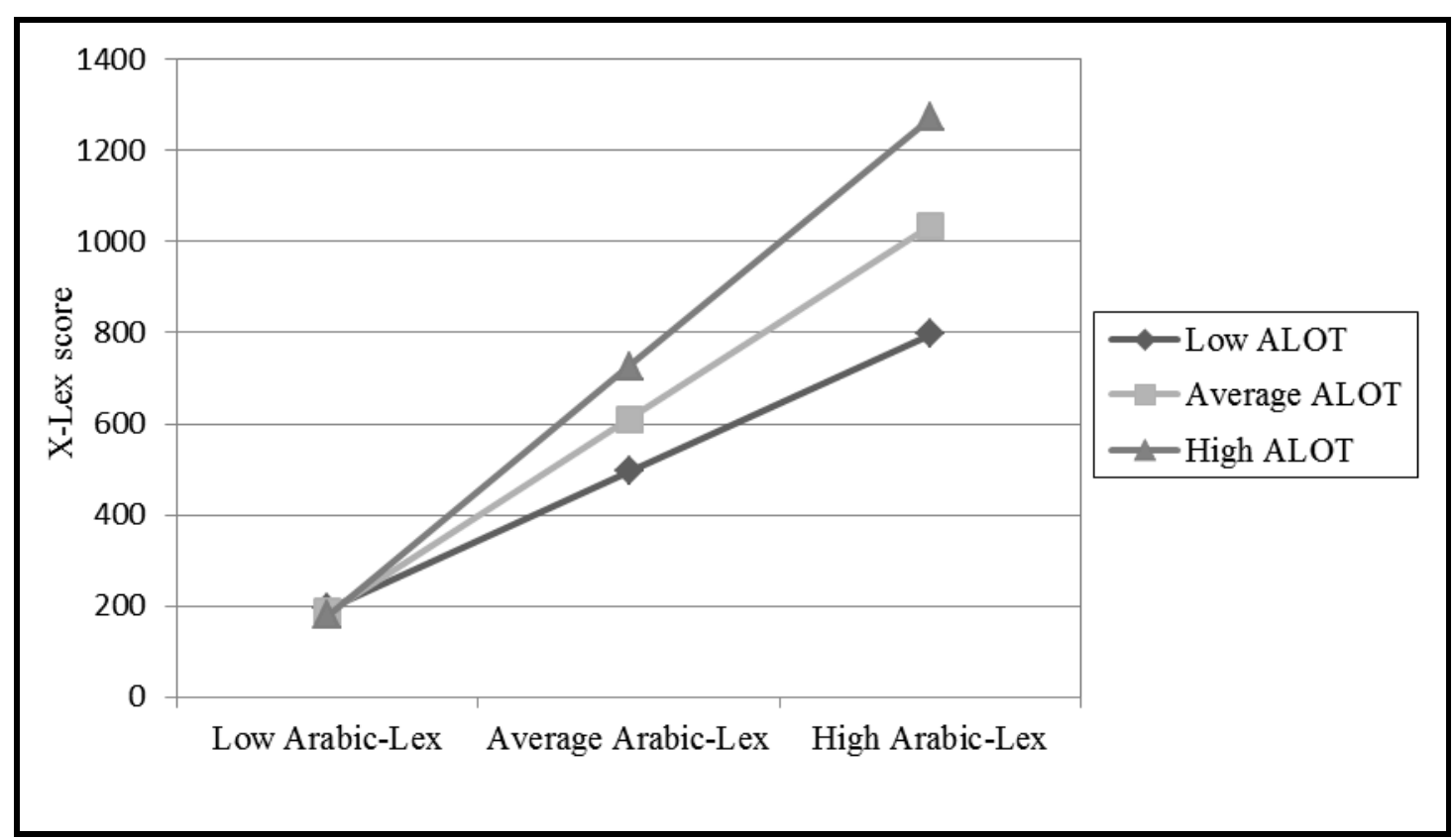

Figure 3. Conditional effect of Arabic-Lex score on X-Lex score at values of the moderator (ALOT score)

To summarize, the relationship between organisational ability and the L1 vocabulary size in Arabic seems straightforward. If a learner is good at rule formation, and individuals must vary in this, then he/she can develop a large Arabic lexicon. This is because vocabulary size in Arabic is less a function of the number of base words, which is small in Arabic (Habash, 2010), and more a function of how many rules a learner knows and can apply to the base words in order to generate a larger vocabulary. 
However, this poses a question in L2 English because a learner cannot transfer this rule or the analytical ability entailed to build a bigger English vocabulary size, since many more words in English are borrowed or created rather than derived. A learner, thus, has to learn these words. So, how can this relationship between the L1 lexical organisational ability and L2 vocabulary size be explained?

One potential answer to this question is that the relationship is mediated through L1 vocabulary size, since having a large number of words ought to mean a learner has a large number of translation equivalents to which a new label can be applied (Baker, 2009). This would support the idea that the bilingual mental lexicon is compound or subordinative in structure rather than coordinate (see for example, De Groot, 1993; Szubko-Sitarek, 2015). However, this does not appear to fully explain why native Arabic speakers have such a problem when learning English. A possible explanation is that native Arabic speakers may only establish connections between English words and Arabic base-words - which are smaller in number - rather than to the derived Arabic words. Learners who possess more base-words in Arabic would be good in building connections between L1 Arabic and L2 English lexicons. Thus, to elicit more useful information in this regard, a word family based vocabulary size test, rather than a narrow European language style lemma test, is needed.

\section{Conclusions}

This paper examined the relationship between L1 lexical organisation and L2 vocabulary acquisition. The findings show that the link between L1 and L2 mental lexicon sizes reported by Masrai and Milton (forthcoming) is supported and the validity of their Arabic-Lex test is reinforced. The study also found, regardless of the assumption that L1 and L2 lexis are separately stored, the two systems appeared to be in communication with each other (Singleton, 1999). However, it should be noted here that the relationship between a given L1 lexical item and L2 lexical item in the mental lexicon will definitely vary from one learner to another, depending on how the words have been acquired and how well they are known. Furthermore, the relationship between an L1 word and L2 word is subject to the degree to which semantic similarity is perceived between the L2 word and L1 word in question.

The second question addressed in this study was whether there is a causal effect of L1 lexical organisation on L2 vocabulary acquisition. Although it is quite hard to disassociate lexical organisation from the overall size of the mental lexicon, an attempt was made to test this kind of relationship. The study showed a high correlation between L1 Arabic lexical organisation and L2 English vocabulary size. Although a high correlation between L1 lexical organisation and L1 vocabulary size was found, a clear conclusion of the effect of L1 lexical organisation, per se, on L2 vocabulary acquisition cannot be clearly drawn.

The third question addressed in this paper was whether there is a relationship between L1 lexical organisation and the size of the L1 mental lexicon. A very strong correlation was found between these two dimensions of the mental lexicon. This relationship was elicited by performing a moderation analysis, suggesting a significant interaction between organisation and size of the L1 lexicon on L2 lexicon size. This could, to a larger extent, confirm that lexical networks and the size of the lexicon are strongly associated elements, and the size of the mental lexicon is a product of a highly sophisticated lexical web, as Aitchison (2003) puts it. 
One final conclusion of this study is that, despite a strong relationship between L1 lexical organisation and L2 vocabulary size being established, the L2 vocabulary size of native Arabic learners is generally small. Therefore, further research might need to revisit the Arabic vocabulary size using a test that includes a word-family definition rather than the lemma convention of word count, and then compare this with L2 vocabulary size. It could be the case that the big Arabic lexicon is actually small when a word-family is used in the testing methodology.

\section{References}

Al-Hazemi, H. (1993). Low-level EFL vocabulary tests for Arabic speakers (Unpublished doctoral dissertation). University of Wales, Swansea.

Alsaif, A. (2011). Investigating vocabulary input and explaining vocabulary uptake among EFL learners in Saudi Arabia (Unpublished doctoral dissertation). Swansea University, Swansea.

Abu-Rabia, S. (2002). Reading in a root-based-morphology language: the case of Arabic. Journal of Research in Reading, 25(3), 299-309.

Agustín Llach, M. (2011). Lexical errors and accuracy in foreign language writing. Bristol; Buffalo: Multilingual Matters.

Aitchison, J. (2003). Words in the mind: An introduction to the mental lexicon. Oxford: Blackwell.

Ausubel, D. A. (1968). Educational psychology: A cognitive view. New York: Holt, Rinehart \& Winston.

Ausubel, D. P. (1964). Adults versus children in second-language learning: Psychological considerations. The Modern Language Journal, 48(7), 420-424.

Bastkowski, M. (2010). Extending the mental lexicon: The L2 mental lexicon. Munich: GRIN Verlag.

Boudelaa, S., \& Marslen-Wilson, W. (2005). Discontinuous morphology in time: Incremental masked priming in Arabic. Language and Cognitive Processes, 20, 207-260.

Boudelaa, S., \& Marslen-Wilson, W. (2010). Aralex: a lexical database for Modern Standard Arabic. Behavior Research Methods, 42(2), 481-487.

Boudelaa, S., Pulvermüller, F., Hauk, O., Shtyrov, Y., \& Marslen-Wilson, W. (2010). Arabic morphology in the neural language system. Journal of Cognitive Neuroscience, 22, 998-1010.

Carroll, S. E. (1992). On cognates. Second Language Research, 8(2), 93-119. 
Channell, J. (1988). Psycholingusitc considerations in the study of L2 vocabulary acquisition. In R. Carter \& M. McCarthy (Eds.), Vocabulary and language teaching (pp. 83-96). London: Longman.

De Groot, A. M. B. (1993). Word-type effects in bilingual processing tasks: Support for a mixed-representational system. In R. Schreuder \& B. Weltens (Eds.), The bilingual lexicon (pp. 27-51). Amsterdam: John Benjamins.

Field, A. (2013). Discovering statistics using IBM SPSS statistics (Fourth ed.). London: SAGE Publications Ltd.

Frost, R., Forster, K. I., \& Deutsch, A. (1997). What can we learn from the morphology of Hebrew? A masked priming investigation of morphological representation. Journal of Experimental Psychology: Learning, Memory, \& Cognition, 23, 829-856.

Giacobbe, J. (1992). A cognitive view of the role of L1 in the L2 acquisition process. Second Language Research, 8(3), 232-250.

Habash, N. Y. (2010). Introduction to Arabic natural language processing. Synthesis Lectures on Human Language Technologies, 3(1), 1-187.

Jiang, N. (2002). Form-meaning mapping in vocabulary acquisition in a second language. Studies in Second Language Acquisition, 24(04), 617-637.

Kersten, S. (2010). The mental lexicon and vocabulary learning: Implication for the foreign language classroom. Tübingen: Narr Verlag

Kroll, J. F., Michael, E., Tokowicz, N., \& Dufour, R. (2002). The development of lexical fluency in a second language. Second Language Research, 18(2), 137-171.

Laufer, B. (1991). Some properties of the L2 mental lexicon as evidenced by lexical confusions. International Review of Applied Linguistics, 29, 317-330.

Littlewood, W. (1984). Foreign and second language learning: Language acquisition research and its implications for the classroom. Cambridge: Cambridge University Press.

Masrai, A., \& Milton, J. (forthcoming). How large is Arabic speakers' L1 mental lexicon: Validating a new Arabic vocabulary size test. Manuscipt in progress.

Ma, Q. (2009). Second language vocabulary acquistion. Bern: Peter Lang.

Meara, P. (1984). The study of lexis in interlanguage. In A. Davies, C. Criper \& A. P. R. Howatt (Eds.), Interlanguage (pp. 225-235). Edinburgh,Scotland: Edinburgh University Press.

Meara, P. (1992). Network structures and vocabulary acquisition in a foreign language. In P. Arnaud \& H. Be'joint (Eds.), Vocabulary and applied linguistics (pp. 62-70).

London: MacMillan Academic and Professional Ltd. 
Meara, P. (1996). The vocabulary knowledge framework. Discussion Paper. Swansea University.

Meara, P. (2009). Connected words: Word associations and second language vocabulary acquisition. Amsterdam: John Benjamins Publishing Company.

Nation, P. (2001). Learning vocabulary in another language. Cambridge: Cambridge University Press.

Ringbom, H. (1983). Borrowing and lexical transfer. Applied Linguistics, 4(3), 207-212.

Schmitt, N. (2000). Vocabulary in language teaching. Cambridge: Cambridge University Press.

Singleton, D. M. (1999). Exploring the second language mental lexicon. Cambridge: Cambridge University Press.

Snow, C. E., \& Kim, Y. S. (2007). Large problem spaces: The challenge of vocabulary for English language learners. In R. K. Wagner, A. Muse \& K. Tannenbaum (Eds.), Vocabulary acquisition and its implications for reading comprehension. New York: Guilford Press.

Szubko-Sitarek, W. (2015). Multilingual lexical recognition in the mental lexicon of third language users. Berlin: Springer-Verlag.

Tang, W., Yu, Q., Crits-Christoph, P., \& Tu, X. M. (2009). A new analytic framework for moderation analysis-moving beyond analytic interactions. Journal of Data Science, 7(3), 313-329.

Van Hell, J. G., \& Kroll, J. F. (2013). Using electrophysiological measures to track the mapping of words to concepts in the bilingual brain: A focus on translation. In J. Altarriba \& L. Isurin (Eds.), Memory, language, and bilingualism: Theoretical and applied approaches (pp. 126-160). New York: Cambridge University Press.

Weinreich, U. (1974). Languages in contact: Findings and problems (8th reprint, first published in 1953 ed.). The Hangue: Mouton \& Co.

Wolter, B. (2001). Comparing the L1 and L2 mental lexicon: A depth of individual word knowledge model. Studies in Second Language Acquisition, 23, 41-69.

Wolter, B. (2006). Lexical network structures and L2 vocabulary acquisition: The role of L1 lexical/conceptual knowledge. Applied Linguistics, 27(4), 741-747. 


\section{Appendices}

\section{Appendix A}

\section{$\underline{\text { Arabic lexical organisation test (ALOT) }}$}

Name (code):

Level:

This test is designed to measure your ability to generate new words from base forms in Arabic. Please select $(\checkmark)$ the appropriate word from the given choices to complete the sentence.

Thank you for your help!

تم تصميم هذا الاختبار لقياس مقدرتك على انتقاق كلمات جديدة من جذور الكلمات في اللغة العربية. فضلاً اختر الكلمة الصحيحة ( ل) من الخبار ات المعطاة لإنكمال الجملة.

شكر أ على المساعدة!

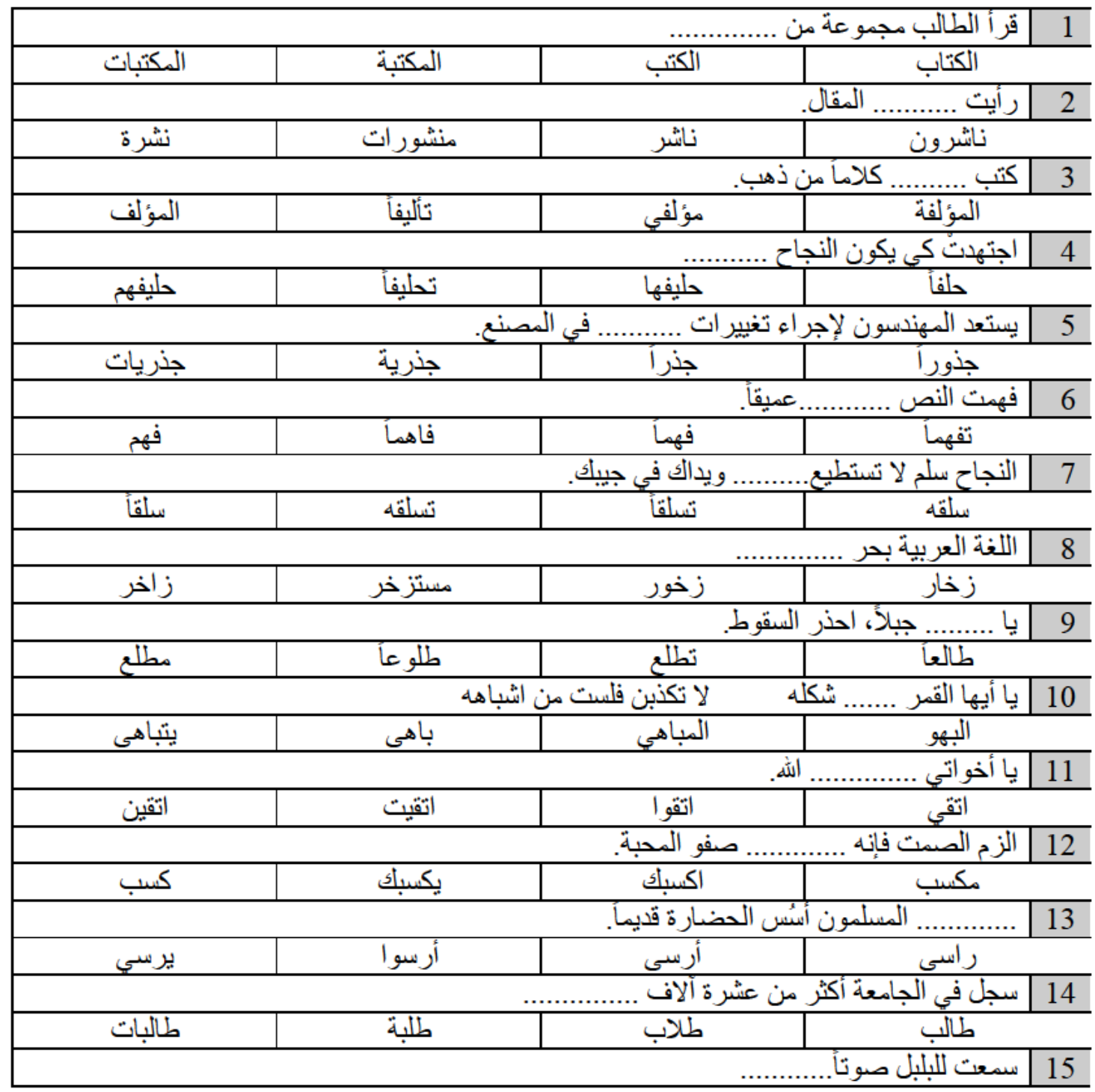




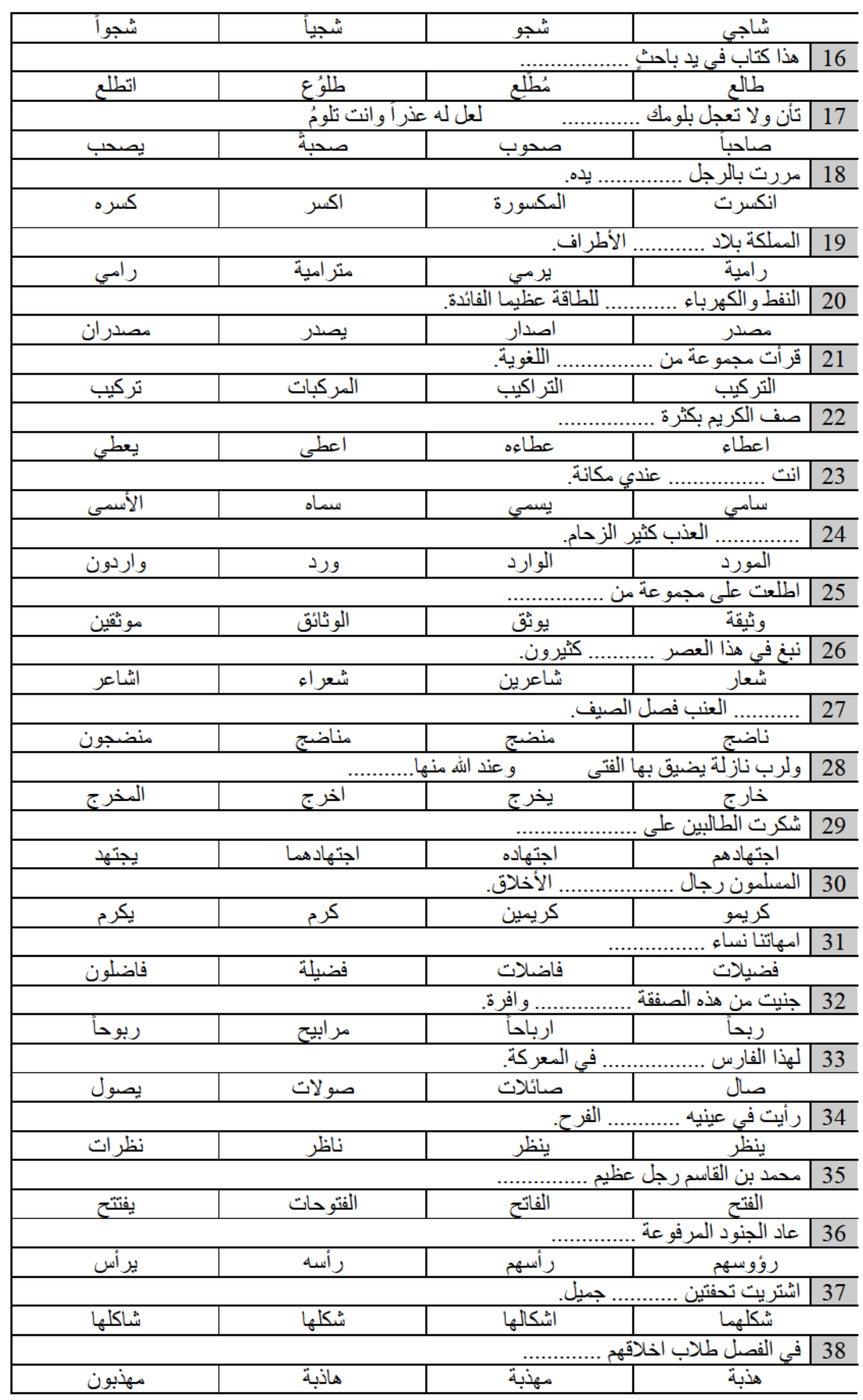




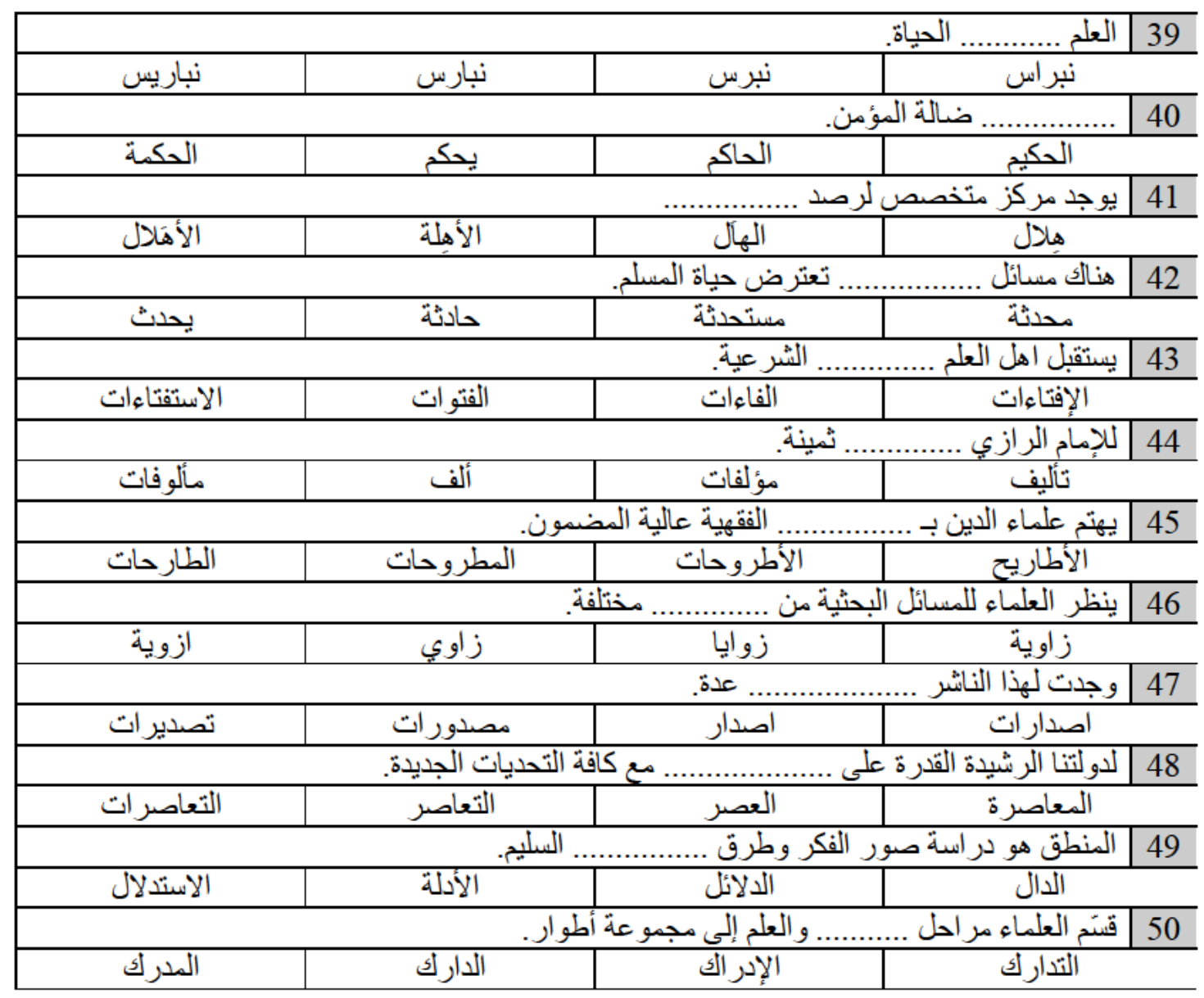

